\title{
Physical Exercise for Active Skin Ulceration Secondary to Peripheral Arterial Occlusive Disease
}

Jefferson Petto, ${ }^{1,2,3,4,5}$ Marvyn de Santana do Sacramento, ${ }^{1,5}$ Fernanda Oliveira Baptista de Almeida, ${ }^{1,3,5}$ Jorge Bomfim Frós de Farias, ${ }^{6 \odot}$ Euvaldo de Almeida Rosa ${ }^{6,7}{ }^{6}$

Faculdade Social da Bahia (FSBA), 'Salvador, BA - Brazil

Escola Bahiana de Medicina e Saúde Pública (EBMSP), ${ }^{2}$ Salvador, BA - Brazil

Faculdade Adventista da Bahia (FADBA), ${ }^{3}$ Cachoeira, BA - Brazil

Universidade Salvador (UNIFACS), ${ }^{4}$ Salvador, BA - Brazil

Clínica Cordis, ${ }^{5}$ Salvador, BA-Brazil

Secretaria de Estado da Saúde da Bahia (SESAB), ${ }^{6}$ Salvador, BA - Brazil

Urgências Médica Cirúrgicas (URMEC), ${ }^{7}$ Santo Antônio de Jesus, BA - Brazil

\section{Introduction}

Peripheral arterial occlusive disease (PAOD) is a chronic, initially subclinical, and characteristically inflammatory disease that mainly affects the carotid arteries and lower limbs. ${ }^{1,2}$

When in the lower limbs, it causes intermittent claudication, associated with a shortened leg gait, cyanotic extremities and decreased muscular force associated with sarcopenia below the obstruction site. At more advanced stages, it can cause ulcerations that are difficult to heal, due to the decrease in blood flow. The final stage of pathophysiology is completed with a trophic lesion and consequent amputation of the affected limb, leading to a decrease in the quality of life and to functional limitations in activities of daily living. ${ }^{3}$ This results in increased costs generated by the treatment and impaired productive capacity of these patients.,4

Chronic systemic arterial hypertension (SAH), diabetes, smoking, and dyslipidemia are the four main triggers of atherosclerotic disease. Usually individuals with lowerlimb PAOD are associated with one or more of these four factors. Therefore, all patients with one of these four factors should be investigated for the presence of PAOD..$^{2,3}$

\section{Keywords}

Peripheral Arterial Disease/complications; Skin Ulcer / complications; Risk Factors; Exercise; Intermittent Claudication; Sarcopenia.
One of the most efficient ways to diagnose lowerlimb PAOD is through the Ankle-Brachial Index (ABI), where the systolic blood pressure in the ankle is divided by the systolic blood pressure of the arm. A result $<0.9$ means a diagnosis of $\mathrm{PAOD}$, even in the absence of specific symptoms. ${ }^{4}$

The nosological diagnosis of lower-limb PAOD is based on pain-free walking time. The Fontaine classification is the most commonly used one. It is divided into four stages: I - asymptomatic (presence of PAOD without symptoms); IIa - claudication above 200 meters and IIb - claudication below 200 meters; III - pain at rest; and stage IV - trophic lesion and consequent amputation of part of the affected limb. ${ }^{4}$

The maximum walking tolerance test is used for both the diagnosis and classification of lower-limb $\mathrm{PAOD}$ as the basis for treatment of this condition, since a cardiovascular and metabolic rehabilitation (CMR) program, using treadmill walking, is considered the treatment that shows the best cost-benefit relation for this disease. ${ }^{5,6}$

Therefore, this report aims at describing how a CMR program using a treadmill improved the clinical and functional condition and stimulated the healing of a heel skin ulceration in a patient with lower-limb PAOD.

\section{Case report}

IAS, a 65-year-old female patient, whose weight was 55 kilos, and height, 1.62 meters, entered the Cardiovascular

Mailing Address: Marvyn de Santana do Sacramento

Rua Rio Grande do Sul, n 356. Postal Code: 41830-140, Pituba, Salvador, BA - Brazil.

E-mail: marvynsantana@gmail.com,marvynsantana@hotmail.com 
Rehabilitation Service of the URMEC Clinic in Santo Antônio de Jesus, BA, Brazil in December 2014, diagnosed with PAOD. The arteriography disclosed $100 \%$ of occlusion in the popliteal, anterior and posterior tibial arteries of the right lower limb.

According to the medical report, the patient was submitted to coronary artery bypass grafting (CABG) with three grafts: distal third of the posterior descending artery, proximal third of anterior descending artery and circumflex artery. She had been diagnosed with systemic arterial hypertension 15 years ago and type II diabetes mellitus for 8 years, with both conditions under pharmacological treatment. She had osteopenia in the pelvic region and in the head of the femur. She reported symptoms of chronic fatigue at moderate exertion, compatible with functional class II heart failure during the anamnesis.

The physical examination disclosed diffuse sarcopenia, mainly in the upper and lower limbs, blood pressure of $180 / 100 \mathrm{mmHg}$. She had an ulceration in the posterior side of the right heel in progress for 24 months, undergoing topical pharmacological treatment (Papain and Chlorhexidine). For the skin ulcer treatment, the patient also reported that she had undergone physical therapy sessions (32 sessions) with laser, microcurrent and $3 \mathrm{MHZ}$ ultrasound. She did not show any signs of pulmonary congestion and cyanosis of the extremities. These findings corroborated the idea of a good prognosis for the heart failure, since it was characterized as noncongestive and warm.

The 24-hour ambulatory blood pressure monitoring (ABPM) showed mean BP of $160 / 90 \mathrm{mmHg}$ with absence of nocturnal dipping. The fasting laboratory tests showed: triglycerides $276 \mathrm{mg} / \mathrm{dL}$, high-density lipoprotein (HDL) of $41 \mathrm{mg} / \mathrm{dL}$, low-density lipoprotein (LDL) of $58 \mathrm{mg} / \mathrm{dL}$, total cholesterol of $154 \mathrm{mg} / \mathrm{dL}$ and glycemia of $172 \mathrm{mg} / \mathrm{dL}$.

At the end of the evaluation, the patient's main complaint was ambulation difficulty, due to the heel ulceration and the difficulties caused by this condition when performing the activities of daily living.

She was receiving treatment with the following drugs: $\mathrm{NPH}$ insulin, $25 \mathrm{IU} / \mathrm{mL}$ at $8 \mathrm{AM}$ and $20 \mathrm{IU} / \mathrm{mL}$ at $8 \mathrm{PM}$; Metformin, $500 \mathrm{mg}$ at $8 \mathrm{AM}$ and $12 \mathrm{PM}$; Olmesartan, $40 \mathrm{mg}$ at $8 \mathrm{AM}$; Indapamide, $1.5 \mathrm{mg}$ at $8 \mathrm{AM}$, Manidipine, $20 \mathrm{mg}$ at $8 \mathrm{AM}$; Atorvastatin, $80 \mathrm{mg}$ at 7 PM; Clopidogrel, $75 \mathrm{mg}$ at 7 PM; and Vitamin D, 1,200 IU twice a week.
Based on the patient's complaints and the possibilities of the exercise program, the aims of the study were: $10-20 \%$ reduction in the fasting glycemia and glycated hemoglobin values; normalization of fasting triglyceride values; reduction of 5 to $10 \mathrm{mmHg}$ in SBP and $5 \mathrm{mmHg}$ in DBP; increase in functional capacity by at least $20 \%$; skin ulceration healing; increased tolerance to walking. An eight-month projection was estimated to reach the goals.

\section{Cardiovascular and Metabolic Rehabilitation Protocol}

The patient started the CMR by performing neuromuscular exercises for the upper and lower limbs, arm cycle ergometer for upper body training and inspiratory muscle training (IMT).

In the first month, the neuromuscular exercises were performed twice a week on alternate days (Mondays and Wednesdays), with the exercises for upper limbs being performed on the first day and those for lower limbs on the second day. The exercises comprised two sets of 20 repetitions with a 2-minute interval between sets, with loads based on Borg's rating of perceived exertion (RPE) scale between 9 and 11. After the first month, the neuromuscular exercise schedule was readjusted to two sets of 12 repetitions with loads that stimulated a Borg scale score between 12 and 15. The load progression occurred monthly until the end of the treatment, which lasted six months.

At the same session, after the neuromuscular exercises, the arm cycle ergometer training was performed for 20 minutes using a passive interval approach (active for five minutes followed by two minutes of passive rest). The load was also based on the Borg scale, being the first and second sets performed with Borg score between 9 to 11 and the last 3 with Borg between 12 and 14. The arm cycle ergometer was used until the third month of treatment.

The IMT was performed at home with $30 \%$ of PImax in 30 daily repetitions carried out in sets of 10 repetitions, seven days a week. The IMT load was readjusted weekly, which persisted until the end of the first three months of treatment. After the third month, the IMT was performed with no more progressive loads.

After three months, a gel insole was manufactured for the ulcerated heel, which contained an orifice at the ulceration site allowing the treadmill training. Therefore, the arm cycle ergometer training was replaced by the treadmill at the beginning of the fourth month of 
treatment. For the treadmill use, a maximum walking tolerance test, described by Petto et al., was applied at a velocity of $1.5 \mathrm{~km} / \mathrm{h}$ on a treadmill without inclination. The maximum walking tolerance road was reached at 280 seconds (4 minutes and 7 seconds).

The training was prescribed based on this test. The first two sets were performed with $60 \%$ and, the last four, with $80 \%$ of the maximum walking tolerance obtained at the test ( 280 seconds) at a speed of $1.5 \mathrm{~km} / \mathrm{h}$, the same speed used in the test. This totaled 1,232 seconds of walking, approximately 4.5 times the total time obtained at the walk tolerance test. The test was performed monthly for the increase in time and speed employed for the training, which lasted three months.

Therefore, the total time of CMR was six months, with the first three months being dedicated to neuromuscular exercises for upper and lower limbs, arm cycle ergometer and IMT, twice a week. In the last three months, the cycle ergometer was replaced by the ergometric treadmill and CMR started to be performed three times a week.

It is important to note that the pharmacological treatment, laser therapy, ultrasound and microcurrent for the ulceration healing were maintained from the beginning to the end of the CMR.

\section{Results}

Table 1 shows the evolution of the metabolic variables after the CMR. The great improvement in the patient's lipid profile and fasting glycemia can be observed, factors that positively contribute to the clinical and functional improvement of patients with PAOD. The reduction in the glycated hemoglobin levels demonstrates the glycemic control improvement throughout the CMR program.

This figure shows that the heel ulceration was healed, after the three-month treadmill training. No ulceration improvement was seen in the first three months of CMR. In addition to the ulceration healing, the patient improved her treadmill performance, being able to carry out uninterrupted walks at a speed of $5.5 \mathrm{~km} / \mathrm{h}$ for 30 minutes.

It is worth emphasizing that this gain probably occurred due to the blood flow improvement in the affected limb, caused by the opening of the collateral circulation and angiogenesis (formation of new capillaries), therefore promoting ulceration healing and walking performance improvement.

\begin{tabular}{|c|c|c|c|}
\hline Variables & Pre-CR & Post-CR & Normal values \\
\hline $\begin{array}{l}\text { Triglycerides } \\
(\mathrm{mg} / \mathrm{dL})\end{array}$ & 276 & 119 & $<150 \mathrm{mg} / \mathrm{dL}$ \\
\hline $\mathrm{HDL}(\mathrm{mg} / \mathrm{dL})$ & 41 & 51 & $>50 \mathrm{mg} / \mathrm{dL}$ \\
\hline LDL (mg/dL) & 58 & 39 & $<130 \mathrm{mg} / \mathrm{dL}$ \\
\hline $\begin{array}{l}\text { Total cholesterol } \\
(\mathrm{mg} / \mathrm{dL})\end{array}$ & 154 & 114 & $<200 \mathrm{mg} / \mathrm{dL}$ \\
\hline $\begin{array}{l}\text { Glycemia } \\
(\mathrm{mg} / \mathrm{dL})\end{array}$ & 172 & 130 & $<100 \mathrm{mg} / \mathrm{dL}$ \\
\hline $\begin{array}{l}\text { Glycated } \\
\text { hemoglobin }(\%)\end{array}$ & 9.8 & 7.8 & $\begin{array}{c}\text { Between } 4.0 \text { and } \\
5.6 \%\end{array}$ \\
\hline $\begin{array}{l}\text { Creatinine } \\
(\mathrm{mg} / \mathrm{dL})\end{array}$ & 1.5 & 1.5 & $\begin{array}{c}\text { Between } 0.6 \text { and } \\
1.1 \mathrm{mg} / \mathrm{dL}\end{array}$ \\
\hline $\begin{array}{l}\text { HDL: high-densi } \\
\text { cardiovascular rel }\end{array}$ & $\begin{array}{l}\text { rotein } \\
\text { ion. }\end{array}$ & low-densi & poprotein; $C R$ : \\
\hline
\end{tabular}

In addition to these improvements, the patient after six months of treatment was able to reduce drug dose for hypertension (Manidipine), diabetes mellitus (NPH and metformin) and dyslipidemia (atorvastatin).

\section{Discussion}

Physical exercise has been increasingly becoming significant in the treatment of peripheral vascular diseases because it is a non-invasive method, it has a positive impact on the quality of life and functional status, in addition to being a low-cost and higheffectiveness treatment. ${ }^{7}$

Locatelli et al., ${ }^{8}$ report that a physical exercise program that combines treadmill walking with neuromuscular exercises (resistance exercises with weights) is the one that significantly increases the maximum pain-free walking distance in patients with lower-limb PAOD and intermittent claudication. That occurs because walking training stimulates the opening of collateral circulation and also angiogenesis. ${ }^{9}$

These two mechanisms are the main responsible ones for the improvement in the perfusion of the affected region, reducing ischemia and its consequences. Specifically in this reported case, the ulceration healing was due mainly to the improved blood irrigation, which 


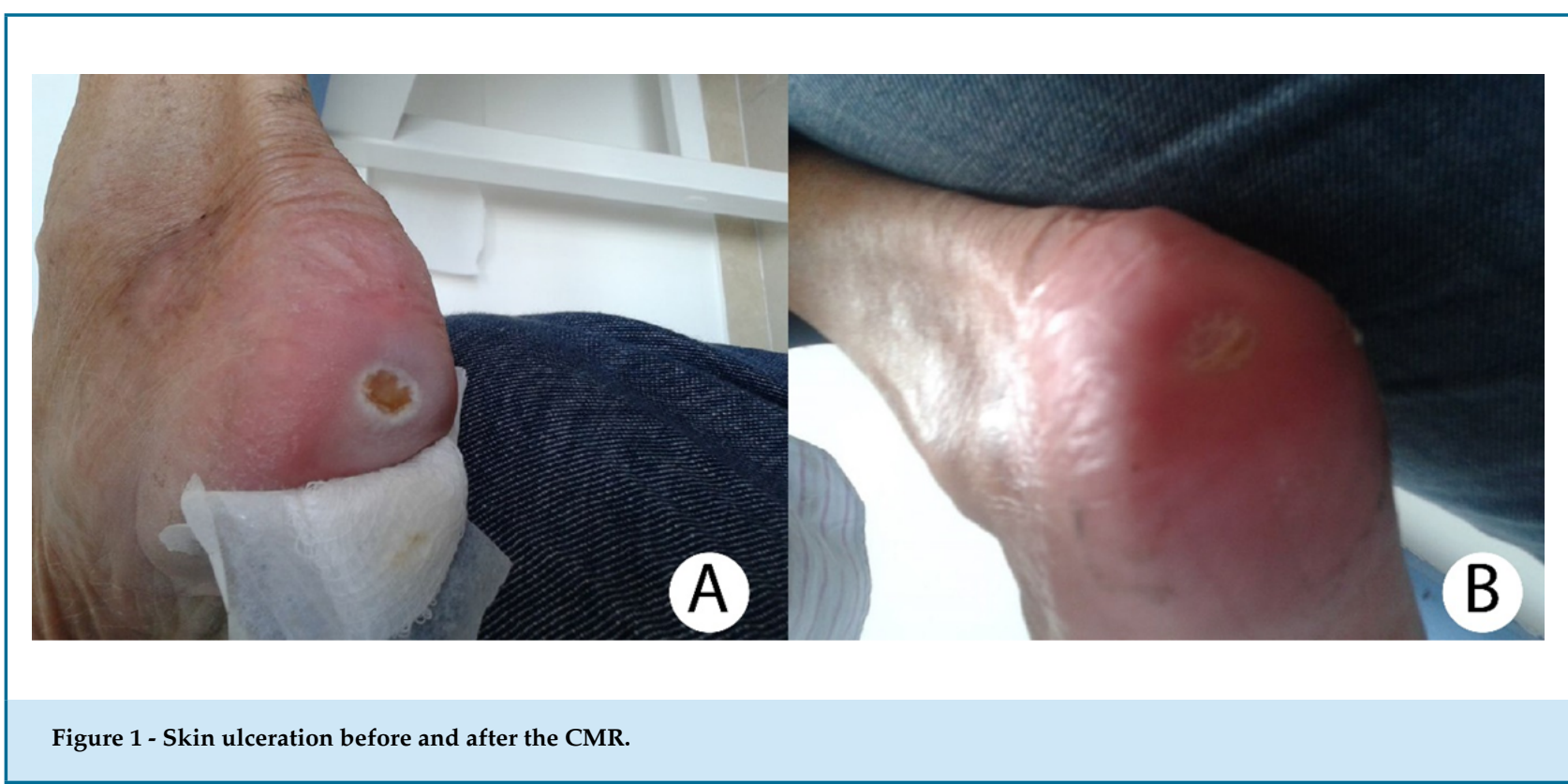

favors the entire tissue healing process. Additionally, CMR resulted in improved glycemia and lipid control, a condition that favors the ulceration healing and controls the evolution of the atherosclerotic disease. ${ }^{7}$

Strongly corroborating this hypothesis, Murphy et al., ${ }^{5}$ carried out a study in which 111 subjects with lower-limb PAOD were randomized into three groups. A group received only pharmacological treatment, a group underwent coronary artery bypass grafting in the region affected by PAOD plus pharmacological treatment and a group that underwent a supervised walking training plus pharmacological treatment. The authors found that after a six-month period, the exercise group increased walking tolerance more than the CABG group and the medication group. The same result was identified in the questionnaire that was applied in this study and investigated the limitation that claudication brings to activities of daily living. It was concluded that, of the three treatments, the supervised walking exercise was the best treatment option, considering the cost-benefit ratio.

However, despite evidence such as this and cases such as the one reported herein, there are few patients with lower-limb PAOD who are referred to CMR services to undergo a specific and supervised treatment.

A study carried out in 2002 by Nunes et al., ${ }^{3}$ reported that more than 180 people a year are amputated because of lower-PAOD in the city of Salvador, state of Bahia, Brazil. There are reports in the literature that support the idea that a CMR program could in many cases avoid amputation. A study published in $2011^{1}$ reports the case of a patient with lower-limb PAOD that avoided amputation after undergoing a supervised treadmill walking program. Such evidence suggests that other patients with lower-limb PAOD may benefit from CMR.

It is also interesting to note that in the case reported herein, before the patient underwent the CMR, she had already undergone unsuccessful physical therapy with laser, ultrasound and microcurrent sessions for the ulceration healing. She had also been undergoing two years of topical pharmacological treatment with no positive response. However, when the pharmacological treatment was associated with CMR and physical therapy, the ulceration healing was attained. It should be noted in this case the fact that the CMR program, using treadmill walking as the main exercise type, was crucial for the patient's clinical and functional improvement and ulceration healing and how the interdisciplinary interaction is essential to optimize the treatment of lower-limb PAOD.

Physical exercise is fundamental for the control of two of the main modifiable risk factors for the development of lower-limb PAOD - diabetes mellitus and dyslipidemia. According to Conte et al., ${ }^{6}$ the main modifiable risk factors for PAOD are dyslipidemia, diabetes mellitus and smoking. Therefore, the visible metabolic improvement in this case, both in triglyceride and plasma lipoprotein levels, as well as glycemia, also favored the patient's clinical and functional improvement. Brandão et al., ${ }^{2}$ reported that each $10 \%$ reduction in total cholesterol 
levels resulted in a reduction of up to $15 \%$ in the risk of mortality due to cardiovascular diseases.

The evidence currently available in the literature is enough to routinely refer patients with lower-limb PAOD to CMR services before having them submitted to more invasive procedures, such as revascularization or angioplasty. The interdisciplinary treatment should be the first option, as it increases the chance of clinical and functional condition improvement, reduces the administration of drugs and prevents surgical treatment and amputations in this population.

\section{Conclusion}

According to this case report, a supervised exercise program on a treadmill combined with neuromuscular exercises was effective in the healing process of the lowerlimb PAOD-related skin ulcer and in the control of the modifiable risk factors that lead to this condition, such as diabetes mellitus and dyslipidemia. This report also aims to encourage more health professionals to prioritize interdisciplinary treatment by referring their patients with PAOD to supervised physical exercise programs.

\section{Author contributions}

Conception and design of the research: Petto J, Farias JBF, Rosa EA. Acquisition of data: Petto J, Almeida
FOB. Analysis and interpretation of the data: Petto J, Sacramento MS, Almeida FOB, Farias JBF, Rosa EA. Statistical analysis: Petto J, Sacramento MS. Writing of the manuscript: Petto J, Sacramento MS. Critical revision of the manuscript for intellectual content: Petto J, Farias JBF, Rosa EA.

\section{Potential Conflict of Interest}

No potential conflict of interest relevant to this article was reported.

\section{Sources of Funding}

There were no external funding sources for this study.

\section{Study Association}

This study is not associated with any thesis or dissertation work.

\section{Ethics approval and consent to participate}

This study was approved by the Ethics Committee of the Universidade Estadual de Feira de Santana under the protocol number 0033.059.000-11. All the procedures in this study were in accordance with the 1975 Helsinki Declaration, updated in 2013. Informed consent was obtained from all participants included in the study.

\section{References}

1. Petto J, Almeida FOB, Vasques LMR. Eficácia de um programa de condicionamento físico intervalado sobre a tolerância a caminhada em um indivíduo com doença arterial obstrutiva periférica. Salvador Fisioter Bras. 2011;12(6):459-62.

2. Brandão AC, Trindade DM, Pinhel MA, Anacleto AM, Godoy JMP, Godoy MF, et al. Avaliação do perfil lipídico na doença arterial periférica. J Vasc Br. 2005;4(2):129-36.

3. Nunes JLB, Araujo Filho JS, Silvany Neto AM, Andrade CS, Duque BC, Costa FPM, et al. Doença Arterial Oclusiva Periférica de membros inferiores em hospitais públicos de salvador-perfil dos pacientes e do atendimento. J Vasc Bras. 2013;1(3):201-6.

4. Herdy AH, López-Jiménez F, Terzic CP, Milani M, Stein R, Carvalho T, et al. Diretriz sul-americana de prevenção e reabilitação cardiovascular. Arq Bras Cardiol. 2014;103(2Suppl.1):1-31.

5. Murphy TP, Cutlip DE, Regensteiner, JG, Mohler ER, Cohen DJ, Reynolds $\mathrm{RR}$, et al. Supervised exercise versus primary stenting for claudication

eesulting From Aortoiliac Peripheral Artery Disease. Circulation. 2012;125(1):130-9.

6. Hirsch AT, Hackal ZJ, Hertzer NR, Bakal CW, Creager MA, Halpern JL, et al. ACC / AHA Guidelines for the management of PAD. J Am Coll Cardiol. 2006;47(6):1239-312.

7. Conte MS, Pomposelli FB, Clair DG, Geraghty PJ, McKinsey JF, McKinsey et al. Society for Vascular Surgery practice guidelines for atherosclerotic occlusive disease of the lower extremities: Management of asymptomatic disease and claudication.. J Vasc Surg. 2015;61(3):2S-41S.

8. Locatelli EC, Pelizzari S, Scapini KB, Leguisamo CP, Silva AB. Exercício físico na doença arterial obstrutiva periférica. J Vasc Bras. 2009;8(3):24754.

9. Gavin TP. Basal and exercise-Induced regulation of skeletal muscle capillarization. Exerc Sport Sci Rev. 2009;37(2):86-92. 